\title{
Managing urinary incontinence in the community
}

\author{
Choon How $\underline{H o w}^{1}$, MMed, FCFP, Hui Min Joanne $\underline{\text { Quah }}{ }^{2}$, MMed, FCFP
}

\begin{abstract}
A stench of urine stronger than usual is apparent when Mrs Lee enters your office with her wheelchair-bound father-in-law for their chronic condition reviews. You decide to see the elderly Mr Lee first, exploring his micturition habits at home. After their domestic helper helped Mr Lee out of your office, you continue the discussion on micturition with Mrs Lee and screen her for urinary incontinence.
\end{abstract}

\section{HOW COMMON IS THIS IN MY PRACTICE? What is urinary incontinence?}

Urinary incontinence is the involuntary loss of urine resulting from pathologic, anatomic or physiologic factors. The two major types of urinary incontinence are stress and urge incontinence. Stress urinary incontinence (SUI) involves the loss of small quantities of urine during an increase in intra-abdominal pressure, which is produced by coughing, sneezing, laughing or exercising. SUI is characterised by outlet incompetence. Urge urinary incontinence (UI) involves urine loss due to abnormal detrusor muscle contractions and is, to some degree, associated with urinary retention. UI is a major component of overactive bladder syndrome, and is characterised by an abrupt and strong desire to void.

Other types of urinary incontinence include overflow, functional and mixed. Overflow incontinence involves a variety of symptoms such as urgency, frequent urination and constant dribbling, and is characterised by urine loss due to overdistension and ineffective emptying of the bladder. Functional incontinence refers to the inability to get to the toilet in time due to acute or chronic physical or mental impairment. Mixed urinary incontinence is the term used to describe the condition in which the symptoms of both SUI and UI are present.

\section{How relevant is this to my practice?}

The prevalence of urinary incontinence in Singapore has been reported to range from $4.6 \%{ }^{(1)}$ to $14.5 \% .^{(2)}$ However, this rate might arise from significant underreporting in the community, as institutional studies often report a higher prevalence. ${ }^{(3)}$ As patients rarely initiate a discussion on urinary continence, the onus is on the astute clinician to elicit information, such as symptoms suggestive of urinary incontinence, from their highrisk patients.

Patients at high risk include the elderly, especially menopausal women with a history of pregnancy and childbirth, medical conditions such as chronic cardiac disease, diabetes mellitus, hypercalcaemia, chronic lung disease, constipation with faecal impaction, neurological conditions (e.g. multiple sclerosis, stroke, spinal cord injuries, lumbar disc disease, Parkinson's disease) and cognitive impairment, and/or other disabilities affecting mobility.

Although urinary incontinence is more common in the elderly and female populations, it is not part of the natural ageing process. Urinary incontinence is also not simply a urological problem - if untreated, it can lead to skin irritation and worsen bed sores. The condition is a common source of social embarrassment, often resulting in adaptive behaviour that may be restrictive and tormenting. This loss of control can damage self-esteem, result in anxiety disorders or even lead to major depression. The care required for an individual with urinary incontinence can increase the caregiver's burden and may lead to premature institutionalisation of elderly family members. Some nursing homes impose a higher charge for applicants with urinary incontinence, reflecting the higher amount of care required for such individuals.

\section{WHAT CAN MY PRACTICE DO? Actively screen high-risk patients}

Clinicians can screen high-risk patients for symptoms of urinary incontinence during the course of regular clinical consultation. An opening question from the clinician typically gives most patients the nudge they need to tell the clinician more about their condition. Depending on the patient's duration and severity of symptoms, as well as predisposing risk factors, the consultation can progress to either identify reversible causes (DIAP(P)ERS; Table $\left.{ }^{(4)}\right)$, especially in the geriatric population, or discuss further investigation and management options. A review by Weiss outlines the drugs that can cause or contribute to urinary incontinence (Table II). ${ }^{(5)}$

As with many urological conditions, quick surveys on how the patient or caregiver is coping with the symptoms and the level of inconvenience experienced by either party are equally

\footnotetext{
${ }^{1}$ Sing Health Polyclinics - Sengkang, ${ }^{2}$ SingHealth Polyclinics - Outram, Singapore

Correspondence: Dr How Choon How, Director, SingHealth Polyclinics - Sengkang, 2 Sengkang Square, Sengkang Community Hub, Singapore 545025. how.choon.how@singhealth.com.sg
} 
Table I. Causes of transient incontinence in the elderly (adapted from Resnick(4)).

\begin{tabular}{|c|c|}
\hline Cause & Notes \\
\hline Delirium & $\begin{array}{l}\text { Results from medical illness or medication. } \\
\text { Incontinence is secondary and abates when } \\
\text { the cause of delirium has been corrected. }\end{array}$ \\
\hline Infection (urinary) & $\begin{array}{l}\text { Asymptomatic bacteriuria does not usually } \\
\text { cause incontinence. }\end{array}$ \\
\hline Atrophic urethritis & $\begin{array}{l}\text { May cause or contribute to incontinence. } \\
\text { Vaginitis responds to topical oestrogen } \\
\text { therapy. }\end{array}$ \\
\hline Pharmaceuticals & $\begin{array}{l}\text { Many drugs can cause or contribute to } \\
\text { incontinence (see Table II), including } \\
\text { non-prescribed agents. }\end{array}$ \\
\hline Psychological & $\begin{array}{l}\text { Severe depression is rarely the cause of } \\
\text { incontinence. }\end{array}$ \\
\hline $\begin{array}{l}\text { Excessive urine } \\
\text { output }\end{array}$ & $\begin{array}{l}\text { Results from large fluid intake, consumption } \\
\text { of diuretic agents, metabolic disorders (e.g. } \\
\text { hyperglycaemia, hypercalcaemia). Nocturnal } \\
\text { incontinence may result from the mobilisation } \\
\text { of fluid from peripheral oedema. }\end{array}$ \\
\hline Restricted mobility & $\begin{array}{l}\text { Often results from overlooked, correctable } \\
\text { causes such as arthritis, postural } \\
\text { hypotension or fear of falling. }\end{array}$ \\
\hline Stool impaction & Disimpaction restores continence. \\
\hline
\end{tabular}

important. Clinicians may choose to do this via either a quality of life tool or an unstructured interview. The impact of the symptoms on the patient or main caregiver is an independent and overriding reason for definitive care, even when the condition is clinically early or mild. The two most common causes of urinary incontinence are urinary tract infection and constipation. Both of these causes can be easily diagnosed and managed at the primary care setting. Behavioural therapy and dietary changes are often dismissed by many clinicians and patients as not being impactful enough to be suggested or attempted.

\section{Take a dietary history}

Clinicians can encourage patients to keep a simple dietary diary that records the total amount of fluid and bladder irritants, such as caffeinated beverages, chocolate, alcohol, acidic fruits, tomatoes, sugar, spicy foods and carbonated beverages, consumed within a 24-hour period. This diary can be reviewed together with the patient in order to jointly identify areas of change and decide on lifestyle modifications to work on before the next clinical review. The lifestyle modifications 'prescribed' to the patient with mild to moderate urinary incontinence can be in the form of annotations in the dietary diary or a simple written action plan.

\section{Review medication records}

A review of the patient's current prescription medications, especially cardiology and antihypertensive agents, and all supplements, including alternative medications or herbal treatments, should be done. Medications such as diuretics, which may worsen incontinence (Table $\left.I^{(5)}\right)$, should be
Table II. Drugs that can cause or contribute to urinary incontinence (adapted from Weiss ${ }^{(5)}$ ).

\begin{tabular}{|c|c|}
\hline Drug class & Mechanism of incontinence \\
\hline \multicolumn{2}{|l|}{$\begin{array}{l}\text { Cause overflow incontinence } \\
\text { Anticholinergics }\end{array}$} \\
\hline - Antidepressants & $\begin{array}{l}\text { Decreased bladder contractions } \\
\text { with retention }\end{array}$ \\
\hline - Antipsychotics & $\begin{array}{l}\text { Decreased bladder contractions } \\
\text { with retention }\end{array}$ \\
\hline - Sedative-hypnotics & $\begin{array}{l}\text { Decreased bladder contractions } \\
\text { with retention }\end{array}$ \\
\hline - Antihistamines & $\begin{array}{l}\text { Decreased bladder contractions } \\
\text { with retention }\end{array}$ \\
\hline \multicolumn{2}{|l|}{ CNS depressants } \\
\hline - Narcotics & $\begin{array}{l}\text { Decreased bladder contractions } \\
\text { with retention }\end{array}$ \\
\hline - Alcohol & $\begin{array}{l}\text { Decreased bladder contractions } \\
\text { with retention }\end{array}$ \\
\hline - Calcium channel blockers & $\begin{array}{l}\text { Decreased bladder contractions } \\
\text { with retention }\end{array}$ \\
\hline - Alpha-adrenergic agonists & $\begin{array}{l}\text { Sphincter contraction with } \\
\text { outflow obstruction }\end{array}$ \\
\hline $\begin{array}{l}\text { Cause stress incontinence } \\
\text { - Alpha-adrenergic } \\
\text { antagonists }\end{array}$ & $\begin{array}{l}\text { Sphincter relaxation with } \\
\text { urinary leakage }\end{array}$ \\
\hline \multicolumn{2}{|l|}{ Cause urge incontinence } \\
\hline - Diuretics & $\begin{array}{l}\text { Contractions stimulated by high } \\
\text { urine flow }\end{array}$ \\
\hline - Caffeine & Diuretic effect \\
\hline - Sedative-hypnotics & $\begin{array}{l}\text { Depressed central inhibition of } \\
\text { micturition }\end{array}$ \\
\hline - Alcohol & $\begin{array}{l}\text { Diuretic effect and depressed } \\
\text { central inhibition }\end{array}$ \\
\hline
\end{tabular}

CNS: central nervous system

reviewed for their indications, and the introduction of a substitute considered.

\section{SOME USEFUL INVESTIGATIONS}

Clinicians need to conduct a general examination of the patient, as well as examinations of the lower abdomen, genitalia/ perineum and lumbosacral spine. Through these examinations, common causes of urinary incontinence, such as the presence of an enlarged prostate in older men or the presence of fistulas and faecal impaction in the rectum secondary to constipation, can be excluded. Most primary care set-ups are able to perform simple urinalysis to exclude or treat urinary tract infection. A basic serum check for renal function can be considered in selected cases. Patients with repeated urine samples that contain traces of blood or persistent abnormalities will need to be referred to a urologist for urinary cytological study, intravenous pyelography and cystourethroscopy. 'In-and-out' urinary catheterisation can also be conducted in the clinic within 5 mins of voiding to assess post-void residual (PVR) urine volume. A PVR urine volume of $>150 \mathrm{~mL}$ indicates incomplete emptying of the bladder and a PVR of $>400 \mathrm{~mL}$ is likely to be indicative of overflow incontinence. Assessment of PVR urine volume via 'in-and-out' urinary catheterisation can be performed as an alternative to urodynamic studies, which can only be conducted in clinics with an ultrasonography set-up or support. 


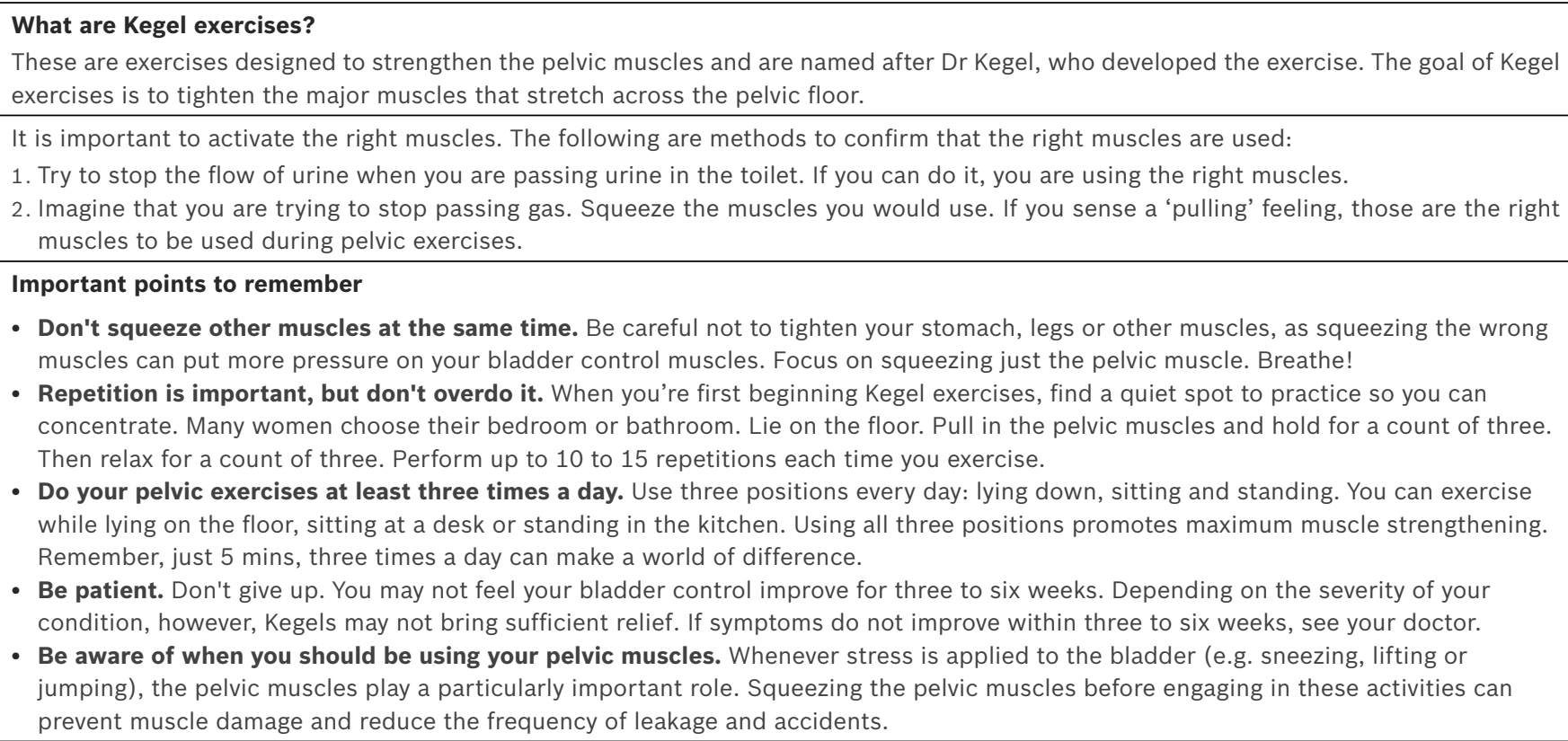

Fig. 1 Chart shows information on Kegel exercises for patients (adapted from patient materials given out by the Department of Obstetrics and Gynaecology, Singapore General Hospital, Singapore).

\section{NON-PHARMACOLOGIC THERAPY}

Simple dietary advice, such as limiting caffeine intake by cutting down on food and beverages like coffee, tea, colas and chocolates, can be offered to affected patients. Caffeine can overload the bladder, causing SUI and UI. Spicy foods and carbonated beverages are bladder irritants and should be avoided in patients with UI. Other useful dietary pointers include adequate fluid intake to prevent constipation and concentrated urine, which can potentiate the irritative effects of dietary materials. For diet and fluid advice to be effective, it should be personalised and targeted at the patient's self-reported diet or the review of the patient's formal dietary intake diary.

Excessive fluid intake may be suspected if the recorded intake in an adult grossly exceeds the typical daily requirement of 1,500-2,400 mL. Restriction of fluid intake an hour or two before bedtime is usually effective in reducing nocturia. Behavioural modifications that can be employed include bladder training, prompted voiding and scheduled toileting. Holding back a full bladder for too long or frequent voiding when the bladder is not full can result in abnormal bladder function. A voiding diary can be issued to affected patients or their caregivers to document each void and episode of incontinence daily. This diary can be reviewed at the next consultation to characterise the type of urinary incontinence affecting the patient.

Pelvic floor exercises such as daily Kegel exercises can increase the strength, control and coordination of pelvic muscles (Fig. 1). These exercises are most effective in women with SUI. Clinical trials of pelvic floor exercises have shown $52 \%-72 \%$ improvement of incontinence in elderly women with SUI. ${ }^{(6)}$ House calls can be offered to patients with functional urinary incontinence, focusing on the patient's ease of getting to or using the toilet at home. These home visits can help the patient's family decide on changes that may improve living conditions and optimise the patient's urinary incontinence management. This also provides an invaluable opportunity for the clinician to become privy to the living conditions of the patient, which will aid in understanding the patient's current health status and family situation, and to point out the presence of potential health threats. Changes to improve the patient's living conditions can come in the form of simple renovation that complements any physical limitations that may impair the patient's ability to get to the toilet, such as removing the kerb at the entrance to the toilet, and installing anti-slip mats over wet floor and additional grab bars in the toilet. If it is too difficult to modify the home, families with sufficient support may also consider introducing a bedside commode.

Nevertheless, the best prevention for urinary incontinence is healthy weight management. Maintaining an optimum weight may decrease urinary incontinence, secondary to decreases in pressure exerted on the bladder and urethral mobility.

\section{PHARMACOLOGIC THERAPY}

Pharmacologic therapy should be used in conjunction with non-pharmacologic therapy.

\section{Pharmacologic options for stress incontinence}

Localised oestrogen replacement therapy may be considered if menopause or other relative oestrogen deficiency is identified as the main cause of urinary incontinence in females with SUI. Topical oestrogen such as vaginal oestrogen may be inserted as a pessary every three months. Alternatively, an oestrogen cream can be applied three times a week. The prescribed dose should be initiated at the smallest recommended dose and slowly titrated upward, based on patient response and tolerance. 


\section{Pharmacologic options for urge incontinence}

Anticholinergics are recommended as the first-line pharmacotherapy in the treatment of urinary incontinence. Tolerodine and oxybutynin are considered standard therapy, but tolerodine can be first considered for use as a muscarinic receptor antagonist, as it has a higher selectivity to bladder receptors and a lower incidence of adverse effects like headache, fatigue and symptoms involving the gastrointestinal tract and central nervous system. Furthermore, tolerodine has not been associated with significant changes in electrocardiogram, blood pressure, or standard clinical chemistry or haematologic variables. Oxybutynin can cause reduced saliva production and worsening constipation that are severe enough to result in up to one in ten children discontinuing its use. ${ }^{(7)}$

Mrs Lee returned to thank you for screening her for urinary incontinence. She reported an improvement in her condition after starting on antibiotics for her urinary tract infection and reducing her coffee intake to a maximum of two servings daily. She has also taken your advice to find out more about minor home adjustments to facilitate her father-in-law's toileting. Her family has also decided to arrange an appointment with you for a house call before confirming the necessary renovations with their contractor.

\section{TAKE HOME MESSAGES}

1. There are many investigatory and management options for the varying types and severity of urinary incontinence that can be managed at the primary care level.

2. Clinicians should actively screen for or initiate a discussion on urinary incontinence, which can be underdiagnosed in the community.

3. Common myths, such as urinary incontinence is part of the normal process of ageing and only invasive or surgical treatment exists for urinary incontinence, should be challenged.

4. Clinicians should seize every opportunity to screen patients for urinary incontinence and render help to patients in the community who have been diagnosed with this condition.
ABSTRACT Urinary incontinence is the involuntary loss of urine. There are many types of incontinence and different management options available, ranging from lifestyle modifications, medication to surgical intervention. Untreated urinary incontinence can result in a myriad of problems, including skin irritations, infections, social phobia, major depression and premature institutionalisation of elderly family members. Common barriers to optimal management include the socially embarrassing nature of the condition, which impedes open discussion, as well as the misperceptions that management must be invasive and the condition cannot be adequately managed within the community. We discuss the common types of incontinence encountered in the community and their management in the primary care setting.

Keywords: pelvic exercises, primary care, stress incontinence, urge incontinence, urinary incontinence

\section{REFERENCES}

1. Cardone A, Tolino A, Iervolino P. [Asymptomatic bacteriuria in gynecologic pathology not connected with pregnancy]. Minerva Ginecol 1977; 29:551-6. Italian.

2. Chan KM, Pang WS, Ee CH, Ding YY, Choo P. Functional status of the elderly in Singapore. Singapore Med J 1999; 40:635-8.

3. Swithinbank LV, Donovan JL, du Heaume JC, et al. Urinary symptoms and incontinence in women: relationships between occurrence, age, and perceived impact. Br Gen Pract 1999; 49:897-900.

4. Resnick NM. Urinary incontinence. Lancet 1995; 346:94-9.

5. Weiss BD. Diagnostic evaluation of urinary incontinence in geriatric patients. Am Fam Physician 1998; 57:2675-84, 2688-90.

6. Burgio KL, Engel BT. Biofeedback-assisted behavioural training for elderly men and women. J Am Geriatr Soc 1990; 38:338-40.

7. Nijman RJ. Role of antimuscarinics in the treatment of nonneurogenic daytime urinary incontinence in children. Urology 2004; 63 (3 suppl 1): 45-50.

\section{RECOMMENDED READING}

1. Society for Continence (Singapore). Clinical Practice Guidelines: Management of Urinary Incontinence. Singapore: Society for Continence, 2008.

2. Ng LG, Lee LS, eds. An Approach to Common Urological Conditions - a Guide for Family Physicians. Singapore: Regent Publishing. In press. 


\section{SINGAPORE MEDICAL COUNCIL CATEGORY 3B CME PROGRAMME}

\section{(Code SMJ 201308A)}

1. Urinary incontinence refers to the involuntary loss of urine resulting from pathologic, anatomic or physiologic factors.

2. Stress urinary incontinence is characterised by a strong desire to void.

3. Urge urinary incontinence is characterised by outlet incompetency.

4. Functional incontinence is characterised by an inability to get to the toilet and use it in time due to acute or chronic physical or mental impairment.

5. Patients will initiate a conversation on urinary continence when it troubles them enough.

6. Patients at high risk for urinary incontinence include the elderly, especially menopausal women with a history of pregnancy and childbirth, medical conditions such as chronic cardiac disease, diabetes mellitus, hypercalcemia, chronic lung disease, constipation with faecal impaction, neurological conditions (e.g. multiple sclerosis, stroke, spinal cord injuries, lumbar disc disease, Parkinson's disease), cognitive impairment and/or other disabilities affecting their mobility.

7. Urinary incontinence is not part of the natural ageing process.

8. Urinary incontinence is only a urological problem and seldom leads to other medical conditions.

9. Urinary incontinence, if left untreated, can lead to infected bed sores, major depression and premature institutionalisation of elderly family members.

10. We can screen high-risk patients by asking an opening question to give them the nudge needed to discuss more about their urinary conditions.

11. The common reversible causes of urinary incontinence can be summarised by the acronym 'DIAP(P)ERS'.

12. In deciding management options, how an affected individual or caregiver copes with urinary incontinence is more important than the severity of the condition's symptoms.

13. The two most common reversible causes of urinary incontinence are urinary tract infection and constipation.

14. Behavioural therapy and dietary changes are seldom suggested or prescribed, as they are not believed to be impactful in the management of urinary incontinence.

15. A simple dietary diary that records the patient's diet and fluid intake can be used to customise dietary changes needed to improve mild to moderate urinary incontinence.

16. Caffeinated beverages, chocolate, alcohol, acidic fruits, tomatoes, sugar, spicy foods and carbonated beverages are bladder irritants.

17. Cardiology and antihypertensive agents can worsen the symptoms of urinary incontinence.

18. Clinical examination can help to exclude the presence of an enlarged prostate, fistulas and faecal impactation as contributory causes of a patient's urinary incontinence.

19. Repeated urine samples with traces of blood can be observed every six months at the clinic till gross haematuria is first noted.

20. Only a trained ultrasonographer with the necessary equipment can record post-void residual urine volume, and this cannot be done at any clinic.

True

False

(1)

$\square$

$\square$

\section{Doctor's particulars:}

Name in full

MCR number

Specialty:

Email address

\footnotetext{
SUBMISSION INSTRUCTIONS:

(1) Log on at the SMJ website: http://www.sma.org.sg/publications/smjcurrentissue.aspx and select the appropriate set of questions. (2) Provide your name, email address and MCR number. (3) Select your answers and click "Submit".

\section{RESULTS:}

(1) Answers will be published in the SMJ October 2013 issue. (2) The MCR numbers of successful candidates will be posted online at the SMJ website by 27 September 2013. (3) Passing mark is $60 \%$. No mark will be deducted for incorrect answers. (4) The SMJ editorial office will submit the list of successful candidates to the Singapore Medical Council. (5) One CME point is awarded for successful candidates.

Deadline for submission: (August 2013 SMJ 3B CME programme): 12 noon, 20 September 2013.
} 